\title{
A prospective polysomnographic study on the evolution of complex sleep apnoea
}

\author{
W. Cassel*, S. Canisius*, H.F. Becker", S. Leistner*, T. Ploch*, A. Jerrentrup*, \\ C. Vogelmeier*, U. Koehler* and J. Heitmann*
}

ABSTRACT: Complex sleep apnoea (CompSA) may be observed following continuous positive airway pressure (CPAP) treatment.

In a prospective study, 675 obstructive sleep apnoea patients (mean age 55.9 yrs; $13.9 \%$ female) participated. Full-night polysomnography was performed at diagnosis, during the first night with stable CPAP and after 3 months of CPAP.

$12.2 \%$ (82 out of 675 patients) had initial CompSA. 28 of those were lost to follow-up. Only 14 out of the remaining 54 patients continued to satisfy criteria for CompSA at follow-up. 16 out of 382 patients not initially diagnosed with CompSA exhibited novel CompSA after 3 months. 30 (6.9\%) out of $\mathbf{4 3 6}$ patients had follow-up CompSA. Individuals with CompSA were 5 yrs older and $\mathbf{4 0 \%}$ had coronary artery disease. At diagnosis, they had similar sleep quality but more central and mixed apnoeas. On the first CPAP night and at follow-up, sleep quality was impaired (more wakefulness after sleep onset) for patients with CompSA. Sleepiness was improved with CPAP, and was similar for patients with or without CompSA at diagnosis and follow-up.

CompSA is not stable over time and is mainly observed in predisposed patients on nights with impaired sleep quality. It remains unclear to what extent sleep impairment is cause or effect of CompSA.

KEYWORDS: Central sleep apnoea, complex sleep apnoea, continuous positive airway pressure, obstructive sleep apnoea, sleep quality

entral breathing disorders observed in patients treated for obstructive sleep apnoea (OSA) by continuous positive airway pressure (CPAP) [1,2] has led to the definition of a new disorder called complex sleep apnoea (CompSA) [3, 4]. Despite a relatively clear definition in the study by MORGENTHALER et al. [4], the term CompSA is frequently applied to patients who experience various problems with CPAP treatment $[5,6]$. Central respiratory event pathophysiology with CPAP is uncertain and probably multifactorial $[1,3,6$, 7]. Several mechanisms have been proposed, such as increased elimination of $\mathrm{CO}_{2}$ and lower arterial $\mathrm{CO}_{2}$ tension $\left(\mathrm{Pa}, \mathrm{CO}_{2}\right)$ below the apnoea threshold, caused by a decrease in upper airway resistance with $\mathrm{CPAP}$, following hyperventilation or due to other reasons [8]. Sleep instability [9] and the transition from wakefulness to sleep can promote central respiratory events.

Most studies on CompSA or central respiratory events with CPAP have the following shortcomings. 1) Classification of CompSA was based on split-night studies [3, 4, 10]. As sleep stages are not evenly distributed over the course of a night [11], full-night studies might yield more representative results. 2) Studies were conducted retrospectively [4, 10, 12-14] and/or with small sample sizes $[3,14] .3)$ Only patients with complex or predominantly central apnoeas with CPAP $[3,13,15]$ at treatment initiation were followed. This precludes the observation of new cases of CompSA that only appear after chronic CPAP treatment. Selection and follow-up of patients with the highest central apnoea index (CAI) will also lead to regression to the mean [16].

While CompSA is a topic of lively discussion $[5,6,17]$, there is a lack of larger prospective studies observing patients with and without CompSA.

We therefore performed a prospective study in consecutive patients with OSA that were started on CPAP treatment in order to: 1) determine the prevalence of CompSA during the first night with stable CPAP application (initial CompSA); 2) determine the prevalence of CompSA after 3 months of CPAP treatment (follow-up CompSA); 3) observe the natural course of CompSA over 3 months; and 4) compare patients suffering from CompSA to those without CompSA both at onset of treatment and after 3 months.

\section{AFFILIATIONS}

*Faculty of Medicine, Philipps

University Marburg, Marburg, and

\#Center for Internal Medicine and

Neurology, Respiratory and Internal Intensive Care Medicine, Asklepios Clinic Barmbek, Hamburg, Germany.

\section{CORRESPONDENCE}

W. Cassel

Faculty of Medicine

Philipps University Marburg

Baldingerstrasse 1

D-35043 Marburg

Germany

E-mail: cassel@med.uni-marburg.de

Received:

Oct 132009

Accepted after revision:

Jan 282011

First published online:

April 042011 


\section{METHODS}

\section{Study design}

Over a period of 24 months, patients with suspected sleep apnoea referred to the sleep disorders centre of the University Hospital in Marburg, Germany received full-night diagnostic polysomnography (PSG) (diagnostic night) in accordance with international standards [18-20]. All patients underwent a full CPAP titration night with polygraphic recording of breathing parameters. On the subsequent night, CPAP with the pressure setting determined the previous night was applied, and sleep and breathing were evaluated by full-night PSG (baseline CPAP night). After $\sim 3$ months, patients were re-evaluated on treatment in the sleep disorders centre by full-night PSG (3-month CPAP night). No sleeping aids were administered during the study nights. For the baseline CPAP night and the 3-month CPAP night, patients were classified into groups with and without CompSA, according to the definition by MORGENTHALER et al. [4]: five or more central apnoeas per hour or predominant periodic breathing pattern with otherwise effective CPAP treatment (i.e. less than five obstructive or mixed apnoeas or hypopnoeas per hour).

Data collection for this study was approved by the ethics committee of the Faculty of Medicine of the Philipps University Marburg (Marburg, Germany).

\section{Patients}

Only patients with OSA ( $<50 \%$ of all respiratory events being central apnoeas [21]) fulfilling the criteria for adult OSA outlined in the International Classification of Sleep Disorders second edition (ICSD-2; [22]), and patients eligible for CPAP therapy and willing to use CPAP were included in the study. Patients with other sleep disorders according to ICSD-2 (e.g. periodic limb movement disorder or narcolepsy) were excluded.

\section{Measurements}

Sleep staging and evaluation of breathing parameters were performed visually by experienced technicians certified by the German Society for Sleep Medicine and Sleep Research according to standard criteria [18, 21, 23], with the exception that sleep stage N4 was not scored separately but included in sleep stage N3. Calibrated inductive plethysmography was used to determine breathing efforts; airflow was detected with a nasal air-pressure transducer. Airflow with CPAP was measured with a pneumotachograph and pressure transducer. Apnoea and hypopnoea scoring were performed according to the research definitions of KUSHIDA et al. [18] except for central apnoeas, which were scored according to the clinical definition, because an oesophageal balloon was lacking in our PSG montage. For the same reason, it was not possible to discern central and obstructive hypopnoeas. Low-amplitude phases of periodic breathing were scored as hypopnoeas or central apnoeas if the respective criteria were fulfilled. Periods of cycling crescendo and decrescendo changes in breathing amplitude were marked. If three or more such periods were present, with a duration of $\geqslant 10$ consecutive minutes, at least once per night and if there were five or more central breathing events per hour of sleep, the label "periodic breathing" was assigned to this recording [22]. Arousals were also scored according to standard criteria [24]. All sleep studies were reviewed by an experienced pulmonary physician and board-certified sleep specialist. Self-rated habitual sleepiness upon diagnosis and at the 3-month follow-up was measured with the Epworth Sleepiness Scale (ESS) [25]. CPAP adherence was determined by reading hours of usage from the built-in meters and dividing this number by the number of days the CPAP device was with the patient. In $\sim 95 \%$ of patients, conventional CPAP was used. The remaining $5 \%$ received CPAP with expiratory pressure relief technology. No auto-CPAP devices were used.

\section{Statistical analysis}

Variables with a skewness $<2$ and kurtosis $<3$ were considered to be sufficiently close to a normal distribution [26]. For these variables, mean and standard deviation (SD) were calculated for descriptive purposes, and these data are presented as mean \pm SD. Medians, and 1st and 3rd quartiles were used to describe data deviating from a normal distribution, and are presented as median (interquartile range (IQR)). Differences between patients with and without CompSA were analysed by means of the Mann-Whitney U-test. Prevalence rates and other frequency differences were assessed for statistical significance by means of the Chi-squared test or Fisher's exact test if expected cell counts were $<5$. For prevalence rates, 95\% confidence intervals (CIs) were calculated. Spearman rank correlation coefficients were calculated to investigate the association between CPAP pressure and the CAI. Odds ratios for CompSA were determined by multiple logistic regression. Statistical significance was assumed for type I error $<0.05$. Calculations were performed using the Statistical Package for Social Sciences (SPSS) for Windows, version 15.01 (SPSS Inc., Chicago, IL, USA).

\section{RESULTS}

675 patients (581 males and 94 females) with OSA receiving CPAP treatment were included in the study. Their mean \pm SD age was $55.9 \pm 11.5 \mathrm{yrs}$ and body mass index was $32.2 \pm 5.7 \mathrm{~kg} \cdot \mathrm{m}^{-2}$. Average ESS score was $10.9 \pm 4.8$.

\section{Diagnosis and treatment initiation}

During the baseline CPAP night, 82 patients had five or more central apnoeas per hour of sleep, while obstructive and mixed events were less than five per hour. This corresponds to a $12.2 \%$ prevalence of CompSA (95\% CI 9.7-14.6\%). Table 1 shows demographic and physical findings of patients with and without CompSA. Patients with CompSA were significantly older $(p=0.001)$. There was a trend towards more patients with CompSA being diagnosed with hypertension (70.7 versus $59.6 \% ; \mathrm{p}=0.053)$ and coronary artery disease (17.1 versus $10.8 \% ; \mathrm{p}=0.097$ ), but fewer with stroke (3.0 versus $7.3 \%$; $p=0.060)$. The presence of congestive heart failure and atrial fibrillation, as well as intake of opioids and benzodiazepines did not differ between patients with and without CompSA. The same was true for the percentage of patients with uvulopalatopharyngoplasty and pacemakers.

No relevant differences in diagnostic sleep efficiency, sleep stage distribution, sleep latency or wake after sleep onset (WASO) were noticeable when comparing patients with and without CompSA. Sleep stages are given as percentage of total sleep time. There was a trend towards higher arousal index (51.4 versus. 46.9 events $\cdot \mathrm{h}^{-1} ; \mathrm{p}=0.061$ ) and significantly more awakenings were observed in CompSA patients (66.1 versus 56.2 awakenings). 


\begin{tabular}{|c|c|c|c|}
\hline \multirow[t]{2}{*}{ TABLE 1} & \multicolumn{3}{|c|}{$\begin{array}{l}\text { Demographic data for patients with and without } \\
\text { initial complex sleep apnoea (CompSA) }\end{array}$} \\
\hline & CompsA & No CompsA & $p$-value \\
\hline Subjects n & 82 & 593 & \\
\hline Age yrs & $59.8 \pm 9.7$ & $55.4 \pm 11.6$ & $0.001^{*}$ \\
\hline BMI $\mathrm{kg} \cdot \mathrm{m}^{-2}$ & $31.8 \pm 5.3$ & $32.3 \pm 5.8$ & 0.516 \\
\hline ESS score & $10.8 \pm 4.8$ & $11.0 \pm 4.8$ & 0.820 \\
\hline Males & 86.6 & 86 & 0.880 \\
\hline Hypertension & 70.7 & 59.6 & 0.053 \\
\hline $\begin{array}{l}\text { Coronary artery } \\
\text { disease }\end{array}$ & 17.1 & 10.8 & 0.097 \\
\hline $\begin{array}{l}\text { Congestive } \\
\text { heart failure }\end{array}$ & 1.2 & 1.2 & 1.000 \\
\hline Atrial fibrillation & 6.1 & 6.3 & 0.957 \\
\hline Stroke & 3.0 & 7.3 & 0.060 \\
\hline Opioids & 1.2 & 1.0 & 0.598 \\
\hline Benzodiazepine & 1.2 & 0.7 & 0.478 \\
\hline UPPP & 0.0 & 0.5 & 1.000 \\
\hline Pacemaker & 1.3 & 0.7 & 0.478 \\
\hline
\end{tabular}

Breathing parameters revealed a clear difference between patients with and without CompSA. Patients with CompSA on the baseline CPAP night had a significantly higher apnoea/ hypopnoea index (AHI) on the diagnostic night, which was due to more central and mixed apnoeas in this group (table 2). Accordingly, more CompSA patients showed periodic breathing during this night.

Table 3 displays polysomnographic results for the baseline CPAP night, which determined the CompSA classification. As expected, breathing disturbances were substantially reduced on the treatment night compared with the diagnostic night (table 2 versus table 3 ).

Slightly reduced sleep efficiency (71.0 versus $74.1 \%$; $p=0.010)$, more stage $\mathrm{N} 1$ sleep (11.2 versus $8.7 \%, \mathrm{p}=0.015)$ and more WASO time (113.7 versus $97.6 \mathrm{~min} ; \mathrm{p}=0.006$ ) were observed in patients with CompSA. CompSA patients continued to have a higher arousal index (28.3 versus 22.7 events $\left.\cdot h^{-1} ; \mathrm{p}<0.001\right)$ and more awakenings (42.3 versus 34.4 awakenings; $p=0.001$ ). By definition, CompSA patients showed a higher CAI (7.4 versus 0.3 events $\left.\cdot h^{-1} ; \mathrm{p}<0.001\right)$ and more of them had periodic breathing. There were also slightly more mixed apnoeas present in patients with CompSA (mixed apnoea index 0.1 versus 0.0 events $\cdot h^{-1} ; \mathrm{p}<0.001$ ). Obstructive events, mean oxygen saturation during sleep and mean effective CPAP pressure were not dependent on the presence of CompSA. No relevant correlation between $\mathrm{CAI}$ and $\mathrm{CPAP}$ pressure during the baseline CPAP night $(r=0.038 ; p=0.326)$ was observed.

\section{Development of CompSA and follow-up results}

The follow-up evaluations took place after a median of 14 weeks (IQR 13-15 weeks; range 8-16 weeks). 501 (74.2\%; 434 males and 67 females) out of the 675 patients included were available

\begin{tabular}{|c|c|c|c|}
\hline \multirow[t]{2}{*}{ TABLE 2} & \multirow[b]{2}{*}{ CompSA } & \multirow{2}{*}{\multicolumn{2}{|c|}{ No CompSA }} \\
\hline & & & \\
\hline Subjects $n$ & 82 & 593 & \\
\hline TST min & $341.4 \pm 87.9$ & $344.2 \pm 81.6$ & 0.733 \\
\hline SE \% & $69.5 \pm 15.6$ & $70.5 \pm 15.5$ & 0.558 \\
\hline SL min & $36.1 \pm 44.9$ & $29.3 \pm 33.7$ & 0.204 \\
\hline N1 \% & $17.7 \pm 14.7$ & $15.9 \pm 14.1$ & 0.286 \\
\hline N2 \% & $50.4 \pm 14.8$ & $51.7 \pm 13.4$ & 0.429 \\
\hline N3 \% & $14.0 \pm 9.1$ & $15.4 \pm 10.1$ & 0.290 \\
\hline REM \% & $18.1 \pm 7.4$ & $17.1 \pm 7.4$ & 0.395 \\
\hline WASO min & $118.8 \pm 67.4$ & $117.1 \pm 71.0$ & 0.657 \\
\hline Arousal index events $\cdot h^{-1}$ & $51.4 \pm 24.4$ & $46.9 \pm 25.3$ & 0.061 \\
\hline Awakenings $\mathrm{n}$ & $66.1 \pm 41.1$ & $56.2 \pm 35.3$ & $0.028^{*}$ \\
\hline Mean $\mathrm{Sa}, \mathrm{O}_{2} \%$ & $92.4 \pm 3.2$ & $92.7 \pm 2.9$ & 0.367 \\
\hline$A H I$ events $\cdot h^{-1}$ & $35.9(22.0-54.5)$ & $26.2(15.2-43.7)$ & $0.003^{*}$ \\
\hline Al events $\cdot h^{-1}$ & $19.7(7.9-34.2)$ & $8.8(2.9-22.6)$ & $<0.001^{*}$ \\
\hline$H I$ events $\cdot h^{-1}$ & $11.4(7.0-18.3)$ & $12.2(6.7-21.6)$ & 0.548 \\
\hline OAl events $\cdot h^{-1}$ & $4.1(0.8-10.8)$ & $4.1(0.5-12.6)$ & 0.908 \\
\hline MAI events $\cdot h^{-1}$ & $4.9(0.6-17.1)$ & $1.0(0.1-5.4)$ & $<0.001^{*}$ \\
\hline CAl events $\cdot h^{-1}$ & $2.0(0.3-4.7)$ & $0.2(0.0-1.2)$ & $<0.001^{*}$ \\
\hline $\begin{array}{l}\text { Patients with periodic } \\
\text { breathing } \%\end{array}$ & 18.3 & 0.8 & $<0.001^{*}$ \\
\hline
\end{tabular}

Data are presented as mean $\pm S D$ or median (interquartile range), unless otherwise stated. TST: total sleep time; SE: sleep efficiency; SL: sleep latency; N1: sleep stage 1; N2: sleep stage 2; N3: sleep stage 3; REM: rapid eye movement; WASO: wake after sleep onset; $\mathrm{Sa}_{2} \mathrm{O}_{2}$ : arterial oxygen saturation AHI: apnoea/hypopnoea index; Al: apnoea index; HI: hypopnoea index; OAI obstructive apnoea index; MAl: mixed apnoea index; CAl: central apnoea index *: $p<0.05$, which was considered significant.

for follow-up. 65 of these discontinued treatment or had no polysomnographic study at follow-up and were, therefore, not available for further study evaluations. Figure 1 summarises the progression of the study and the number of patients with and without CompSA available for follow-up.

There was no relevant difference in the proportion of patients not available for follow-up after 3 months (34.2 versus $35.6 \%$; fig. 1). 20 out of 82 patients with initial CompSA and 154 out of 593 patients without initial CompSA were lost to follow-up $(p=0.76)$; eight out of 82 CompSA patients and 57 out of 593 patients without CompSA did not continue on CPAP or had no polysomnographic study $(\mathrm{p}=0.98)$.

During the 3-month CPAP night PSG, 30 patients fulfilled the criteria for CompSA. The prevalence of CompSA was significantly $(\mathrm{p}=0.006)$ reduced from 12.2 to $6.9 \%$ (95\% CI $4.5-9.3 \%)$.

40 out of the 54 patients with initial CompSA who were available for follow-up had no CompSA in the follow-up PSG. 16 out of the 30 patients with follow-up CompSA had no initial CompSA. Details on progression of OSA (no CompSA) and CompSA can be found in figure 2. 


\begin{tabular}{|c|c|c|c|}
\hline \multirow[t]{2}{*}{ TABLE 3} & \multicolumn{3}{|c|}{$\begin{array}{l}\text { Polysomnography results from the baseline } \\
\text { continuous positive airway pressure (CPAP) } \\
\text { night for patients with and without initial complex } \\
\text { sleep apnoea (CompSA) }\end{array}$} \\
\hline & CompSA & No CompSA & p-value \\
\hline Subjects $n$ & 82 & 593 & \\
\hline TST min & $341.3 \pm 67.8$ & $350.1 \pm 69.8$ & 0.203 \\
\hline SE \% & $71.0 \pm 11.7$ & $74.1 \pm 12.7$ & $0.010^{*}$ \\
\hline SL min & $31.7 \pm 25.2$ & $29.8 \pm 27.5$ & 0.232 \\
\hline N1 \% & $11.2 \pm 8.8$ & $8.7 \pm 6.9$ & $0.015^{\star}$ \\
\hline N2 \% & $44.8 \pm 12.8$ & $45.5 \pm 11.9$ & 0.471 \\
\hline N3 \% & $22.1 \pm 10.5$ & $23.5 \pm 10.1$ & 0.263 \\
\hline REM \% & $21.9 \pm 6.7$ & $22.4 \pm 7.0$ & 0.635 \\
\hline WASO min & $113.7 \pm 72.1$ & $97.6 \pm 63.5$ & $0.006^{*}$ \\
\hline Arousal index events $\cdot h^{-1}$ & $28.3 \pm 15.1$ & $22.7 \pm 13.2$ & $<0.001^{*}$ \\
\hline Awakenings $\mathrm{n}$ & $42.3 \pm 20.4$ & $34.4 \pm 15.3$ & $0.001^{*}$ \\
\hline Mean $\mathrm{Sa}, \mathrm{O}_{2} \%$ & $94.4 \pm 2.0$ & $94.6 \pm 1.8$ & 0.863 \\
\hline CPAP pressure $\mathrm{cmH}_{2} \mathrm{O}$ & $7.5 \pm 1.6$ & $7.4 \pm 1.8$ & 0.501 \\
\hline$A H I$ events $\cdot h^{-1}$ & $10.4(7.5-17.1)$ & $2.0(0.5-4.3)$ & $<0.001^{*}$ \\
\hline Al events $\cdot h^{-1}$ & $7.8(6.5-12.5)$ & $0.6(0.0-2.0)$ & $<0.001^{*}$ \\
\hline$H I$ events $\cdot h^{-1}$ & $0.9(0.0-4.2)$ & $0.7(0.0-2.4)$ & 0.226 \\
\hline OAl events $\cdot h^{-1}$ & $0.0(0.0-0.1)$ & $0.0(0.0-0.0)$ & 0.134 \\
\hline MAI events $\cdot h^{-1}$ & $0.1(0.0-0.5)$ & $0.0(0.0-0.1)$ & $<0.001^{*}$ \\
\hline CAI events $\cdot h^{-1}$ & $7.4(6.0-10.9)$ & $0.3(0.0-1.4)$ & $<0.001^{*}$ \\
\hline $\begin{array}{l}\text { Patients with periodic } \\
\text { breathing } \%\end{array}$ & 41.5 & 0.0 & $<0.001^{*}$ \\
\hline
\end{tabular}

Data are presented as mean $\pm \mathrm{SD}$ or median (interquartile range), unless otherwise stated. TST: total sleep time; SE: sleep efficiency; SL: sleep latency; N1: sleep stage 1; N2: sleep stage 2; N3: sleep stage 3; REM: rapid eye movement; WASO: wake after sleep onset; $\mathrm{Sa}_{2} \mathrm{O}_{2}$ : arterial oxygen saturation; AHI: apnoea/hypopnoea index; Al: apnoea index; HI: hypopnoea index; OAl: obstructive apnoea index; MAl: mixed apnoea index; CAl: central apnoea index. *: $p<0.05$, which was considered significant.

Only 14 (3.2\%) out of the 436 patients available for follow-up had CompSA both at the initial diagnosis and follow-up PSG.

Differences between follow-up CompSA and no CompSA were similar to those found between CompSA and no CompSA at baseline. This is true despite the fact that the two subgroups of patients with CompSA at baseline and follow-up did not have a large overlap (fig. 2).

Again, patients with CompSA were older (61.0 versus 55.2 yrs; $\mathrm{p}=0.005$ ), but did not differ in standardised body weight and habitual sleepiness (table 4). At follow-up, fewer patients with CompSA were male (73.3 versus $88.9 \%$; $=0.02$ ). Despite slightly lower nightly CPAP use in absolute numbers for patients with CompSA at follow-up, this difference failed to reach statistical significance $(p=0.192)$. More patients in the follow-up CompSA group were diagnosed with hypertension (76.7 versus $56.2 \% ; \mathrm{p}=0.028)$ and coronary artery disease (40 versus $8.4 \%$; $\mathrm{p}<0.001)$.

Going back to the diagnostic night before treatment, patients with follow-up CompSA in the 3-month CPAP night exhibited a higher CAI (3.7 versus 0.3 events $\cdot \mathrm{h}^{-1} ; \mathrm{p}<0.001$ ) and mixed

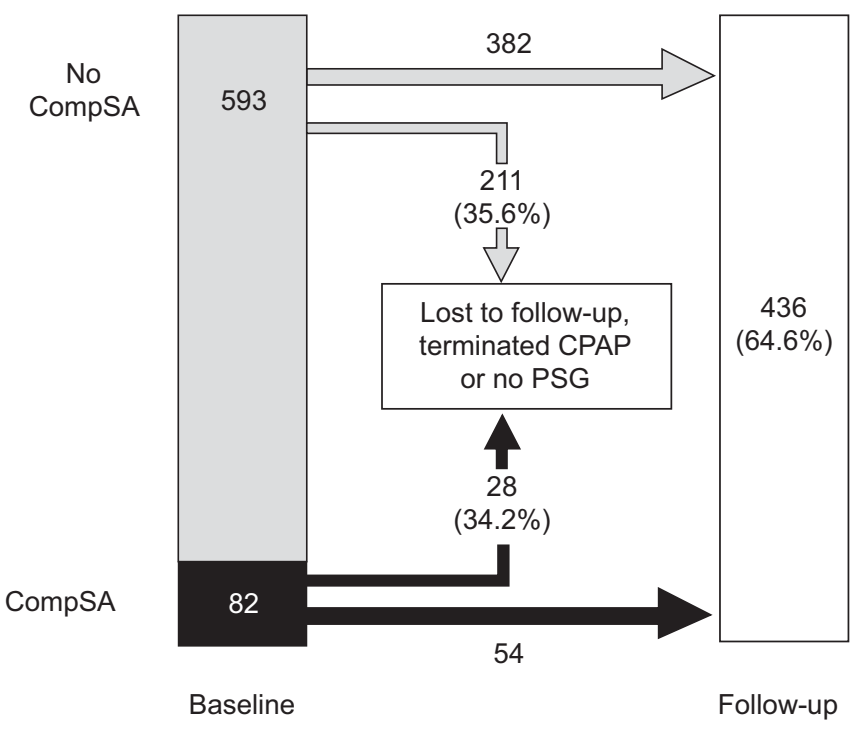

FIGURE 1. Number of patients available for and lost to the 3-month follow-up. CompSA: complex sleep apnoea; CPAP: continuous positive airway pressure; PSG: polysomnography.

apnoea index (9.9 versus 1.2 events $\left.\cdot \mathrm{h}^{-1} ; \mathrm{p}<0.001\right)$, as well as more periodic breathing, whilst no clinically or statistically significant difference in the obstructive apnoea index was present (1.8 versus 4.9 events $\cdot h^{-1} ; \mathrm{p}=0.232$ ). Sleep variables in the diagnostic night 3 months prior revealed a trend towards more awakenings and lower sleep efficiency in the patients with CompSA at follow-up. Table 5 displays, in detail, sleep and breathing parameters of the diagnostic night for patients with and without follow-up CompSA.

In an effort to predict CompSA on the 3-month CPAP night from demographic variables and diagnostic sleep data, variables that differentiated the groups with and without follow-up CompSA at least at the $\mathrm{p}<0.10$ level were entered into a logistic regression model. More central (OR for CAI 1.23;

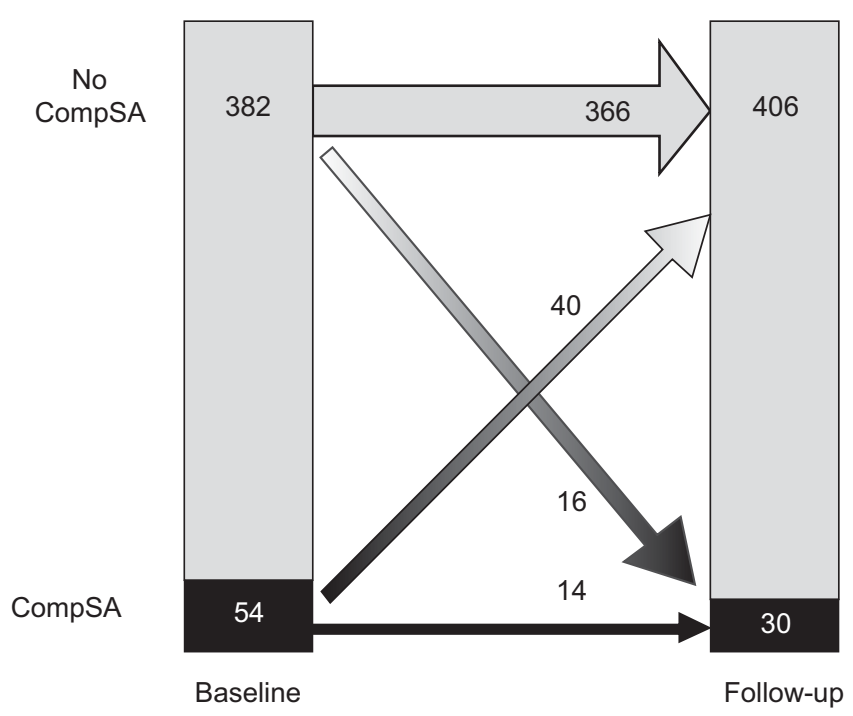

FIGURE 2. Number of patients with complex sleep apnoea (CompSA) and no CompSA over the 3-month study period. 


\begin{tabular}{|c|c|c|c|}
\hline \multirow[t]{2}{*}{ TABLE 4} & \multicolumn{3}{|c|}{$\begin{array}{l}\text { Demographic data for patients with and without } \\
\text { follow-up complex sleep apnoea (CompSA) }\end{array}$} \\
\hline & Follow-up CompsA & $\begin{array}{c}\text { No follow-up } \\
\text { CompSA }\end{array}$ & $\mathrm{p}$-value \\
\hline Subjects n & 30 & 406 & \\
\hline Age yrs & $61.0 \pm 9.1$ & $55.2 \pm 11.3$ & $0.005^{\star}$ \\
\hline BMI $\mathbf{k g} \cdot \mathrm{m}^{-2}$ & $30.8 \pm 3.9$ & $32.4 \pm 5.7$ & 0.290 \\
\hline ESS score & $7.3 \pm 3.9$ & $6.5 \pm 3.7$ & 0.301 \\
\hline Males & 73.3 & 88.9 & $0.020^{*}$ \\
\hline $\begin{array}{l}\text { CPAP adherence } \\
\text { h. } \text { night }^{-1}\end{array}$ & $4.4 \pm 1.7$ & $5.0 \pm 2.0$ & 0.192 \\
\hline Hypertension & 76.7 & 56.2 & $0.028^{*}$ \\
\hline $\begin{array}{l}\text { Coronary artery } \\
\text { disease }\end{array}$ & 40.0 & 8.4 & $<0.001^{*}$ \\
\hline $\begin{array}{l}\text { Congestive heart } \\
\text { failure }\end{array}$ & 0.0 & 0.7 & 1.000 \\
\hline Atrial fibrillation & 13.3 & 6.7 & 0.256 \\
\hline Stroke & 3.2 & 6.7 & 0.276 \\
\hline Opioids & 0.0 & 1.0 & 0.751 \\
\hline Benzodiazepine & 3.3 & 1.0 & 0.301 \\
\hline UPPP & 3.3 & 0.2 & 0.133 \\
\hline Pacemaker & 3.3 & 0.7 & 0.249 \\
\hline $\begin{array}{l}\text { Data are presented } \\
\text { index; ESS: Epwo } \\
\text { pressure; UPPP: uv } \\
\text { significant. }\end{array}$ & $\begin{array}{l}\text { S mean } \pm \text { SD or } \% \text {, unless } \\
\text { Sleepiness Scale; } \\
\text { opalatopharyngoplasty. }\end{array}$ & $\begin{array}{l}\text { Otherwise stated } \\
\text { AP: continuous } \\
: \text { p }<0.05 \text {, which }\end{array}$ & $\begin{array}{l}\text { body mass } \\
\text { tive airway } \\
\text { considered }\end{array}$ \\
\hline
\end{tabular}

$\mathrm{p}<0.001)$ and mixed apnoeas (OR 1.03; $\mathrm{p}=0.037)$ during the diagnostic night increased the risk for follow-up CompSA, whereas obstructive apnoeas, sleep efficiency and awakenings were not significant predictors of CompSA. Male sex reduced the OR for CompSA (OR 0.29; $\mathrm{p}=0.031$ ) and a diagnosis of coronary artery disease clearly increased it (OR 8.89; $\mathrm{p}<0.001$ ), but the presence of hypertension did not alter the odds ratio for CompSA significantly.

In the 3-month CPAP PSG, patients with follow-up CompSA had a clearly shorter sleep duration (318.4 versus 357.6 min; $\mathrm{p}=0.002)$, which was mainly due to more time spent awake after sleep onset (116.8 versus $74.6 \mathrm{~min} ; \mathrm{p}=0.001)$. Accordingly, sleep efficiency was lower (66.3 versus $75.6 \%$; $<<0.001)$. A higher arousal index (31.7 versus 23.8 events $\left.\cdot \mathrm{h}^{-1} ; \mathrm{p}<0.001\right)$ and more awakenings (46.5 versus 34.0; $\mathrm{p}=0.001$ ) were recorded in patients with follow-up CompSA. Table 6 shows breathing parameters for the follow-up treatment night.

By definition, the CAI in the two subgroups differed significantly (8.4 versus 0.1 events $\left.\cdot \mathrm{h}^{-1} ; \mathrm{p}<0.001\right)$, which is probably the reason for the higher AHI in patients with CompSA (11.2 versus 1.4 events $\left.\cdot \mathrm{h}^{-1} ; \mathrm{p}<0.001\right)$. Periodic breathing was more frequent in follow-up CompSA patients. The amount of obstructive apnoeas did not differ for both groups. Mean oxygen saturation during sleep and the mean effective CPAP pressure were also not different for patients with and without CompSA. No clinically or statistically significant correlation between CAI and CPAP pressure on the 3-month CPAP night was found $(r=0.05 ; p=0.302)$.

\begin{tabular}{|c|c|c|c|c|}
\hline \multirow[t]{2}{*}{ TABLE 5} & \multicolumn{4}{|c|}{$\begin{array}{l}\text { Polysomnography results from the diagnostic } \\
\text { night for patients with and without follow-up } \\
\text { complex sleep apnoea (CompSA) }\end{array}$} \\
\hline & & $\begin{array}{l}\text { Follow-up } \\
\text { CompsA }\end{array}$ & $\begin{array}{l}\text { No follow-up } \\
\text { CompsA }\end{array}$ & p-value \\
\hline \multicolumn{2}{|l|}{ Subjects $\mathrm{n}$} & 30 & 406 & \\
\hline \multicolumn{2}{|l|}{ TST $\min$} & $332.7 \pm 75.0$ & $351.8 \pm 82.5$ & 0.132 \\
\hline \multicolumn{2}{|l|}{ SE \% } & $67.0 \pm 15.3$ & $72.0 \pm 15.2$ & 0.073 \\
\hline \multicolumn{2}{|l|}{ SL min } & $40.8 \pm 53.6$ & $28.1 \pm 33.8$ & 0.363 \\
\hline \multicolumn{2}{|l|}{ N1 \% } & $14.7 \pm 14.5$ & $15.1 \pm 13.8$ & 0.595 \\
\hline \multicolumn{2}{|l|}{ N2 \% } & $50.2 \pm 14.0$ & $52.6 \pm 13.7$ & 0.347 \\
\hline \multicolumn{2}{|l|}{ N3 \% } & $17.9 \pm 11.0$ & $14.9 \pm 9.6$ & 0.199 \\
\hline \multicolumn{2}{|l|}{ REM \% } & $17.4 \pm 5.7$ & $17.5 \pm 7.0$ & 0.967 \\
\hline \multicolumn{2}{|l|}{ WASO min } & $127.0 \pm 76.7$ & $111.0 \pm 69.4$ & 0.284 \\
\hline \multicolumn{2}{|c|}{ Arousal index events $\cdot h^{-1}$} & $49.3 \pm 25.3$ & $47.6 \pm 25.1$ & 0.615 \\
\hline \multicolumn{2}{|c|}{ Awakening events $n$} & $65.5 \pm 38.3$ & $56.5 \pm 35.6$ & 0.077 \\
\hline \multicolumn{2}{|c|}{ Mean $\mathrm{Sa}, \mathrm{O}_{2} \%$} & $92.9 \pm 2.1$ & $92.6 \pm 3.0$ & 0.977 \\
\hline \multicolumn{2}{|c|}{ AHI events $\cdot h^{-1}$} & $35.9(23.8-54.9)$ & $26.8(16.6-45.1)$ & $0.060^{*}$ \\
\hline \multicolumn{2}{|c|}{ Al events $\cdot h^{-1}$} & $23.3(8.4-32.8)$ & $10.1(3.6-23.7)$ & $0.004^{*}$ \\
\hline \multicolumn{2}{|c|}{$H I$ events $\cdot h^{-1}$} & $11.2(4.7-19.8)$ & $12.6(7.3-21.6)$ & 0.461 \\
\hline \multicolumn{2}{|c|}{ OAI events $\cdot h^{-1}$} & $1.8(0.5-7.7)$ & $4.9(0.8-13.4)$ & 0.232 \\
\hline \multicolumn{2}{|c|}{ MAl events $\cdot h^{-1}$} & $9.9(1.9-20.9)$ & $1.2(0.1-6.2)$ & $<0.001^{*}$ \\
\hline \multicolumn{2}{|c|}{ CAl events $\cdot h^{-1}$} & $3.7(1.2-6.0)$ & $0.3(0.0-1.2)$ & $<0.001^{*}$ \\
\hline \multicolumn{2}{|c|}{$\begin{array}{l}\text { Patients with periodic } \\
\text { breathing } \%\end{array}$} & 30.0 & 1.0 & $<0.001^{*}$ \\
\hline
\end{tabular}

Data are presented as mean \pm SD or median (interquartile range), unless otherwise stated. TST: total sleep time; SE: sleep efficiency; SL: sleep latency; N1: sleep stage 1; N2: sleep stage 2; N3: sleep stage 3; REM: rapid eye movement; WASO: wake after sleep onset; $\mathrm{Sa}_{2} \mathrm{O}_{2}$ : arterial oxygen saturation; AHI: apnoea/hypopnoea index; Al: apnoea index; HI: hypopnoea index; OAI: obstructive apnoea index; MAl: mixed apnoea index; CAl: central apnoea index *: $p<0.05$, which was considered significant.

\section{DISCUSSION}

In this prospective observational study, the prevalence of CompSA fell from $12.2 \%$ to $6.9 \%$ in 3 months with treatment by fixed CPAP. Only $3.2 \%$ of follow-up patients had CompSA at both time-points. Patients with CompSA were older than those without and slept worse during study nights in which CompSA was determined. More of them suffered from coronary artery disease and they had more pre-existing central apnoeas. No relevant differences in sleepiness between patients with and without CompSA were observed.

\section{Initial CompSA}

The $95 \%$ CI of the $12.2 \%$ prevalence of initial CompSA ranged from 9.7 to $14.6 \%$. This is close to results from MORGENTHALER et al. [4] and LEHMAN et al. [14], but higher than prevalence rates found in recent studies by ENDO et al. [12] and JAVAHERI et al. [13] (table 7). We could not replicate male dominance and slightly younger age in CompSA, as found by most other authors. Our sleepiness scores are similar to other results $[4,13]$.

Our sample's age profile differs only from the study of ENDO et al. [12], who studied younger patients. All other studies determined CompSA on titration nights or in the titration part 


$\begin{array}{lccc}\text { TABLE } 6 & \begin{array}{c}\text { Polysomnography results from the 3-month } \\ \text { continuous positive airway pressure (CPAP) }\end{array} \\ \text { night for patients with and without follow-up } \\ \text { complex sleep apnoea (CompSA) }\end{array}$

Data are presented as mean $\pm S D$ or median (interquartile range), unless otherwise stated. TST: total sleep time; SE: sleep efficiency; SL: sleep latency; N1: sleep stage 1; N2: sleep stage 2; N3: sleep stage 3; REM: rapid eye movement; WASO: wake after sleep onset; $\mathrm{Sa}_{1} \mathrm{O}_{2}$ : arterial oxygen saturation; $\mathrm{AHI}$ : apnoea/hypopnoea index; Al: apnoea index; HI: hypopnoea index; OAl: obstructive apnoea index; MAl: mixed apnoea index; CAl: central apnoea index. *: $p<0.05$, which was considered significant.

of split-night studies. This could account for differences from our results, which were collected during full-night PSG with stable CPAP at the previously established treatment pressure. Furthermore, the sample in the study by LEHMAN et al. [14] included patients with central sleep apnoea. There are also genetic differences with a probable impact on sleep and breathing [27] between the Japanese sample in the study by ENDO et al. [12] and our German Caucasian population.

\section{Initial CompSA versus effectively treated OSA}

Except for slightly more awakenings and arousals, diagnostic PSG sleep quality did not differ between patients with and without initial CompSA. This confirms the results of MORGENTHALER et al. [4]. JAVAHERI et al. [13] found reduced sleep efficiency and lighter sleep in their diagnostic study of CompSA patients compared with matched controls. As our controls were not matched, different results have to be expected. In accordance with other studies [4, 12-14], CompSA patients exhibited higher diagnostic central and mixed apnoea indices, indicating a pre-existing elevated chemical control system instability [28]. This is also reflected in the higher fraction of patients with periodic breathing.

In accordance with MORGENTHALER et al. [4] and JAVAHERI et al. [13], lower sleep efficiency and more sleep stage N1 was observed in CompSA patients' baseline CPAP nights. They also clearly spent more time awake (113.7 versus $97.6 \mathrm{~min}$; $\mathrm{p}=0.006)$ after sleep onset. It remains uncertain whether worse sleep on the baseline CPAP night was caused by CompSA $[7,17]$ or whether the causal relationship is the other way round: $\mathrm{Pa}_{1} \mathrm{CO}_{2}$ fluctuations below the apnoeic threshold occurred in the transition to light sleep [29-31]. Thus, more awakenings, more stage N1 sleep and more WASO could lead to more central apnoeas $[1,6,15]$.

The mean effective CPAP pressure did not differ for patients with and without CompSA and, in contrast to the study by JAVAHERI et al. [13], we found no relevant correlation between CPAP pressure and CAI. Their correlation was significant only if isolated patients requiring high CPAP levels (up to $19 \mathrm{cmH}_{2} \mathrm{O}$ ) were included. The maximum pressure in our sample was $15 \mathrm{cmH}_{2} \mathrm{O}$. Central breathing disorders were probably not caused by elevated CPAP pressures triggering the Hering-Breuer reflex [32].

\section{Stability of CompSA}

$74.1 \%$ (40 out of 54 ) of patients with initial CompSA showed no CompSA at the 3-month follow-up PSG. JAVAHERI et al. [13] observed a similar resolution rate of $78.6 \%$ (33 out of 42 patients) after 5-6 weeks of CPAP. KUZNIAR et al. [3] reported that seven $(53.9 \%)$ out of their 13 CompSA patients did not fulfil the criteria for CompSA after an average of 195 days CPAP. They retrospectively observed only patients with CPAP problems, which might account for their lower resolution rate. Another study in a small patient group found resolution of central sleep apnoea in $12(85.7 \%)$ out of 14 patients after 812 weeks of stable CPAP [15]. In summary, the published data on stability of CompSA corresponds well to our results.

To our knowledge, our study is the first reporting follow-up PSG data of patients with no initial CompSA. 16 (4.2\%) out of these 382 patients available for follow-up developed CompSA over the observation period and accounted for $\sim 50 \%$ of the 30 follow-up CompSA patients.

CompSA prevalence was thus reduced from $12.2 \%$ to $6.9 \%$ in the 3-month PSG. Low stability of CompSA and its reduction with CPAP is probably multifactorial. Low re-test reliability of sleep-disordered breathing [33] and the arbitrary definition of complex sleep apnoea (CAI $\geqslant 5$ events $\cdot h^{-1}$ ) contribute to these effects. A possible physiological explanation for a high resolution rate of CompSA after prolonged CPAP treatment may be normalisation of the under-damped chemoreflex control system with increased $\mathrm{CO}_{2}$ reserve and decreased controller gain under CPAP [34].

Even though we found stable CompSA to be rare, its long-term consequences are unknown [13]. In individual patients with excessive sleepiness potentially caused by CompSA or patients with poor CPAP adherence, pressure support servoventilation should be used to eliminate central apnoeas [35]. As we have shown that CompSA can emerge later on in the course of CPAP treatment, repeated long-term monitoring of clinical 
TABLE 7 Key data from studies on the prevalence of complex sleep apnoea (CompSA)

\begin{tabular}{|c|c|c|c|c|c|c|}
\hline & \multicolumn{4}{|c|}{ Previous studies [ref.] } & \multicolumn{2}{|c|}{ Present study } \\
\hline & MoRgENTHALER et al. [4] & LEHMAN et al. [14] & ENDo et al. [12] & JAVAHERI et al. [13] & Baseline & Follow-up \\
\hline Sample size $n$ & 223 & 99 & 1312 & 1286 & 675 & 436 \\
\hline Prevalence \% & 15 & 13.1 & 5 & 6.5 & 12.2 & 6.9 \\
\hline When determined & Split night & Split night, titration & Titration night & Titration night & Stable CPAP & Stable CPAP \\
\hline ESS score & 11.4 versus 11 & NA & NA & 11 versus $10^{\#}$ & 10.8 versus 11 & 7.3 versus 6.5 \\
\hline
\end{tabular}

data and respiratory disorders data stored in current CPAP machines is recommended.

\section{Follow-up CompSA: demographics and sleep}

Most of the differences observed between patients with and without initial CompSA were also present for the 30 patients with follow-up CompSA, even though 16 of them had no CompSA at baseline. Follow-up CompSA patients were older and had more central and mixed apnoeas in the diagnostic study. Diagnostic sleep quality was quite similar for both groups except for a trend towards lower sleep efficiency and more arousals in patients with follow-up CompSA.

On the 3-month CPAP night, patients with follow-up CompSA had a shorter total sleep time and lower sleep efficiency, mainly due to much longer WASO time (116.8 versus 74.6 min; $\mathrm{p}<0.001)$. They also exhibited more arousals and awakenings and, of course, clearly more central apnoeas. CPAP pressure was not different for both groups and did not correlate with the CAI. Patients with and without follow-up CompSA showed no pronounced difference in CPAP adherence.

It is uncertain whether the impaired sleep of patients with follow-up CompSA also occurred in the home environment or just in the 3-month CPAP night. The similar ESS scores of both groups at follow-up, which fall into the normal range of healthy subjects with similar age [36], seem to indicate that both patients with and without follow-up CompSA did not suffer from chronically impaired recuperation after CPAP was started.

The trend towards more patients with hypertension and coronary artery disease in initial CompSA had stabilised over the 3-month observation period. Hypertension (76.7 versus $56.2 \% ; \mathrm{p}=0.028$ ) and, even more so, coronary artery disease $(40.0$ versus $8.4 \% ; \mathrm{p}<0.001)$ (table 4 ) were significantly more frequent in patients with follow-up CompSA. We see this result as support for the pathophysiological link between coronary artery disease and occurrence of central apnoeas reported in the literature [37].

The surprising finding of more female patients in the followup CompSA group (26.7 versus $11.1 \%$; $\mathrm{p}=0.020$ ) is difficult to explain. One could speculate that transitory bad sleep during the PSG night is promoted by less sleepiness (ESS scores were improved with CPAP and in the normal range) and more susceptibility to disturbing factors, such as the PSG montage. There is a possibility that the latter has more effect on female OSA patients, for whom more sensitivity to factors disturbing sleep has been reported [38]. As observed in one of the first studies describing central apnoeas with CPAP [1], central apnoeas often appear in wake-sleep transition. Thus, more females with follow-up CompSA could hint at the pathogenetic role of impaired sleep for central apnoeas. However, the increase in the proportion of patients with periodic breathing to $66.7 \%$ on the 3-month CPAP night and the very high prevalence of coronary artery disease in follow-up CompSA patients is evidence for an underlying condition promoting central apnoeas. Accordingly, coronary artery disease and pre-existing central apnoeas were the best predictors for follow-up CompSA.

\section{Limitations and strength of this study}

The strengths of this study are the large sample size, the prospective layout, the follow-up of both patients with and without CompSA, and the fact that all PSGs were full-night studies.

Due to the observational, noninterfering nature of this study, particular methods could not be applied. These include nocturnal $\mathrm{Pa}, \mathrm{CO}_{2}$ measurements, the use of an oesophageal balloon to discern central, mixed and obstructive events in the best way, blood gas analysis, and analysis of the response to $\mathrm{CO}_{2}$. Limited resources and the large number of patients made it impossible to perform in-depth evaluations, such as sleep stage-dependent analysis of breathing disorders. The patient population has a referential bias that is typical for a German sleep disorders centre. Patient samples collected in the context of different healthcare systems will differ from our sample.

Even though the relatively large sample size for most comparisons between patients with and without CompSA would have allowed the use of the t-test, the nonparametric MannWhitney U-test was chosen in the present study as the t-test is not robust if distributions are extremely skewed [26], as it is the case, for example, for the AHI with CPAP treatment.

In long-term observation studies, patients are lost to follow-up. $65 \%$ of our baseline patients were available for follow-up. This rate is in the range to be expected for CPAP follow-up [39-41]. In the recent study by JAVAHERI et al. [13], 50\% of patients with 
initial CompSA were available for follow-up; patients without CompSA were not re-examined at all. Equivalent numbers of patients with and without initial CompSA were available for follow-up. Patients lost to and available for follow-up were not different in demographics or sleep variables in the diagnostic night and first stable CPAP night (data not shown). These results do not indicate a specific bias for patient loss to follow-up, but as CompSA may be more frequent among patients who abandon treatment, our follow-up prevalence estimate of $6.9 \%$ is probably an underestimation of the true magnitude of the problem.

\section{Conclusion}

CompSA was not stable over the 3-month observation period. Very few patients had CompSA at baseline and follow-up. The novel finding that patients with initially sufficient treatment exhibited CompSA in the follow-up PSG shows that central breathing disorders with CPAP should not be described as a stable phenomenon, but rather as a dynamic process. Longer treatment with CPAP seems to reduce central apnoeas, as the prevalence of CompSA fell from 12.2 to $6.9 \%$. While this is a clear reduction, it means that these patients still have evidence of respiratory instability and chemoreflex influences after 3 months of CPAP.

Patients who develop CompSA have a higher prevalence of coronary artery disease, a higher diagnostic CAI and more pre-existing periodic breathing. They are otherwise not very different from patients without CompSA in demographics and baseline diagnostic sleep parameters. While neither baseline sleepiness or follow-up sleepiness is different for patients with and without CompSA, their sleep with CPAP both at baseline and follow-up is worse than the sleep of patients without CompSA. More awakenings and longer WASO time could both be causes of CompSA or its effects.

In order to address this issue, interventional studies on the effect of artificially improved (e.g. hypnotics) or impaired sleep (e.g. noise) on wake-sleep transitions and the relative risk of central apnoeas in different sleep stages seem to be promising approaches.

\section{STATEMENT OF INTEREST}

None declared.

\section{ACKNOWLEDGEMENTS}

The authors thank A. Loh (Clinassess GmbH, Leverkusen, Germany) and T. Speicher (Faculty of Medicine, Philipps University Marburg, Marburg, Germany) for their valuable contribution to data collection and data handling. We also thank A. Bozarth (Faculty of Biology, Philipps University Marburg), L. Tanner and T. Tanner (both Algonquin College, Ottawa, ON, Canada) for editing the manuscript and correcting errors of the German authors.

This article is dedicated to the memory of Prof. Jörg Hermann Peter (Faculty of Medicine, Philipps University Marburg).

\section{REFERENCES}

1 Marrone O, Stallone A, Salvaggio A, et al. Occurrence of breathing disorders during CPAP administration in obstructive sleep apnoea syndrome. Eur Respir J 1991; 4: 660-666.

2 Thomas RJ, Terzano MG, Parrino L, et al. Obstructive sleepdisordered breathing with a dominant cyclic alternating pattern - a recognizable polysomnographic variant with practical clinical implications. Sleep 2004; 27: 229-234.
3 Kuzniar TJ, Pusalavidyasagar S, Gay PC, et al. Natural course of complex sleep apnea - a retrospective study. Sleep Breath 2008; 12: 135-139.

4 Morgenthaler TI, Kagramanov V, Hanak V, et al. Complex sleep apnea syndrome: is it a unique clinical syndrome? Sleep 2006; 29: 1203-1209.

5 Brown LK, Casey KR. Complex sleep apnea: the hedgehog and the fox. Curr Opin Pulm Med 2007; 13: 473-478.

6 Malhotra A, Bertisch S, Wellman A. Complex sleep apnea: it isn't really a disease. J Clin Sleep Med 2008; 4: 406-408.

7 Gilmartin GS, Daly RW, Thomas RJ. Recognition and management of complex sleep-disordered breathing. Curr Opin Pulm Med 2005; 11: 485-493.

8 Eckert DJ, Jordan AS, Merchia P, et al. Central sleep apnea: pathophysiology and treatment. Chest 2007; 131: 595-607.

9 Younes M. Role of arousals in the pathogenesis of obstructive sleep apnea. Am J Respir Crit Care Med 2004; 169: 623-633.

10 Pusalavidyasagar SS, Olson EJ, Gay PC, et al. Treatment of complex sleep apnea syndrome: a retrospective comparative review. Sleep Med 2006; 7: 474-479.

11 Peter H, Penzel T, Peter JH. Enzyklopädie der Schlafmedizin. [Encyclopaedia of Sleep Medicine.] 1st Edn. Heidelberg, Springer Medizin Verlag, 2007.

12 Endo Y, Suzuki M, Inoue Y, et al. Prevalence of complex sleep apnea among Japanese patients with sleep apnea syndrome. Tohoku J Exp Med 2008; 215: 349-354.

13 Javaheri S, Smith J, Chung E. The prevalence and natural history of complex sleep apnea. J Clin Sleep Med 2009; 5: 205-211.

14 Lehman S, Antic NA, Thompson C, et al. Central sleep apnea on commencement of continuous positive airway pressure in patients with a primary diagnosis of obstructive sleep apnea-hypopnea. J Clin Sleep Med 2007; 3: 462-466.

15 Dernaika T, Tawk M, Nazir S, et al. The significance and outcome of continuous positive airway pressure-related central sleep apnea during split-night sleep studies. Chest 2007; 132: 81-87.

16 Stelzl I. Fehler und Fallen der Statistik. [Errors and Pitfalls in Statistics]. Berne, Verlag Hans Huber, 1982.

17 Gay PC. Complex sleep apnea: it really is a disease. J Clin Sleep Med 2008; 4: 403-405.

18 Kushida CA, Littner MR, Morgenthaler $\mathrm{T}$, et al. Practice parameters for the indications for polysomnography and related procedures: an update for 2005. Sleep 2005; 28: 499-521.

19 Penzel T, Brandenburg U. [Diagnostic methods and standards in sleep medicine]. Internist (Berl) 1996; 37: 442-453.

20 Penzel T, Conradt R. Computer based sleep recording and analysis. Sleep Med Rev 2000; 4: 131-148.

21 Sleep-related breathing disorders in adults: recommendations for syndrome definition and measurement techniques in clinical research. The Report of an American Academy of Sleep Medicine Task Force. Sleep 1999; 22: 667-689.

22 American Academy of Sleep Medicine. The International Classification of Sleep Disorders. 2nd Edn. Darien, American Academy of Sleep Medicine, 2005.

23 Rechtschaffen A, Kales A. A Manual of Standardized Terminology: Techniques and Scoring System for Sleep Stages of Human Subjects. Los Angeles, UCLA Brain Information Service/Brain Research Institute, 1968.

24 EEG arousals: scoring rules and examples: a preliminary report from the Sleep Disorders Atlas Task Force of the American Sleep Disorders Association. Sleep 1992; 15: 173-184.

25 Johns MW. A new method for measuring daytime sleepiness: the Epworth sleepiness scale. Sleep 1991; 14: 540-545.

26 Bortz J. Statistik für Human- und Sozialwissenschaftler. [Statistics for Human and Social Sciences]. Heidelberg, Springer Medizin Verlag, 2004.

27 Villaneuva AT, Buchanan PR, Yee BJ, et al. Ethnicity and obstructive sleep apnoea. Sleep Med Rev 2005; 9: 419-436. 
28 Younes M, Ostrowski M, Thompson W, et al. Chemical control stability in patients with obstructive sleep apnea. Am J Respir Crit Care Med 2001; 163: 1181-1190.

29 Jordan AS, McEvoy RD, Edwards JK, et al. The influence of gender and upper airway resistance on the ventilatory response to arousal in obstructive sleep apnoea in humans. J Physiol 2004; 558: 993-1004.

30 Pack AI, Cola MF, Goldszmidt A, et al. Correlation between oscillations in ventilation and frequency content of the electroencephalogram. J Appl Physiol 1992; 72: 985-992.

31 Skatrud JB, Dempsey JA. Interaction of sleep state and chemical stimuli in sustaining rhythmic ventilation. J Appl Physiol 1983; 55: 813-822.

32 Tobin MJ. Principles and Practice of Mechanical Ventilation, 2nd Edn. Chicago, McGraw-Hill Professional, 2006.

33 Le BO, Hoffmann G, Tecco J, et al. Mild to moderate sleep respiratory events: one negative night may not be enough. Chest 2000; 118: 353-359.

34 Salloum A, Rowley JA, Mateika JH, et al. Increased propensity for central apnea in patients with obstructive sleep apnea: effect of nasal continuous positive airway pressure. Am J Respir Crit Care Med 2010; 181: 189-193.
35 Javaheri S, Malik A, Smith J, et al. Adaptive pressure support servoventilation: a novel treatment for sleep apnea associated with use of opioids. J Clin Sleep Med 2008; 4: 305-310.

36 Sauter C, Popp R, Danker-Hopfer H, et al. Normative values of the german Epworth Sleepiness Scale - results from a multicenter study. Somnologie 2008; 11: 272-278.

37 Takama N, Kurabayashi M. Possibility of close relationship between sleep disorder breathing and acute coronary syndrome. J Cardiol 2007; 49: 171-177.

38 Resta O, Carpanano GE, Lacedonia D, et al. Gender difference in sleep profile of severely obese patients with obstructive sleep apnea (OSA). Respir Med 2005; 99: 91-96.

39 Damjanovic D, Fluck A, Bremer $\mathrm{H}$, et al. Compliance in sleep apnoea therapy: influence of home care support and pressure mode. Eur Respir J 2009; 33: 804-811.

40 Jean Wiese H, Boethel C, Phillips B, et al. CPAP compliance: video education may help! Sleep Med 2005; 6: 171-174.

41 Middleton S, Vermeulen W, Byth K, et al. Treatment of obstructive sleep apnoea in Samoa progressively reduces daytime blood pressure over 6 months. Respirology 2009; 14: 404-410. 